\title{
Variation in bronchial responsiveness in the European Community Respiratory Health Survey (ECRHS)
}

\author{
S. Chinn, P. Burney, D. Jarvis, C. Luczynska on behalf of the European \\ Community Respiratory Health Survey (ECRHS)
}

Variation in bronchial responsiveness in the European Community Respiratory Health Survey (ECRHS). S. Chinn, P. Burney, D. Jarvis, C. Luczynska on behalf of the European Community Respiratory Health Survey (ECRHS). CERS Journals Ltd 1997. ABSTRACT: Attempts to compare bronchial responsiveness between populations have been hampered by between-study differences in the pharmacological agent of provocation, the method of administration and the summary statistic employed. The European Community Respiratory Health Survey used methacholine challenge delivered by Mefar dosimeter according to a standardized protocol used in 35 centres in 16 countries.

Data were obtained from 13,161 men and women, aged 20-44 yrs at the start of the study. The dose of methacholine producing a $20 \%$ fall in forced expiratory volume in one second (FEV1) (PD20) and the regression coefficient of percentage decline in FEV1 with log dose, were calculated ("slope", after transformation), with and without calibration of nebulizers by weight and adjustment for nonresponse bias. Standardization for baseline lung function and variation in smoking prevalence was applied to slope.

Results were robust to whichever summary measure was used, and to the various adjustments. Responsiveness was low in Iceland and Switzerland, and in most centres in Sweden, Italy and Spain, and high in New Zealand, Australia, the USA, Britain, France, Denmark and Germany.

Bronchial responsiveness varies considerably in Europe, and high levels are not confined to the English-speaking world.

Eur Respir J 1997; 10: 2495-2501.

Bronchial challenge has been used for over 20 yrs, and there have been several epidemiological studies of risk factors for bronchial responsiveness. However, there are relatively few prevalence studies in the general population, and most of these have been in Englishspeaking countries. Neukirch and CARTIER [1] identified 12 studies, eight using histamine challenge, three methacholine and one cold air, with a variety of cut-off points to define reactivity, and differing age ranges. Two comparative studies in children have been published [2, 3], one involving four countries and one involving two, but to date no comparative data on adults from different countries have been reported.

The European Community Respiratory Health Survey (ECRHS) is a multicentre study of the variation in the prevalence, risk factors and management of asthma throughout the European Union and elsewhere [4], and includes measurement of bronchial response to methacholine challenge. Results are reported here from 35 centres in 16 countries which have provided usable data.

\section{Methods}

\section{Sampling}

The protocol for the ECRHS has been described in detail elsewhere $[4,5]$. Briefly, participating centres selec-
United Medical and Dental Schools of Guy's and St. Thomas' Hospitals, London, UK.

Correspondence: S. Chinn

Dept of Public Health Medicine

UMDS St. Thomas' Campus London SE1 7EH

UK

Keywords: Bronchial provocation tests epidemiology

methacholine

multi-centre study

Received: December 301996 Accepted after revision July 41997 ted an area defined by pre-existing administrative boundaries, with a population of at least 150,000 people. Where possible an up-to-date sampling frame was used to select randomly at least 1,500 men and 1,500 women aged 20-44 yrs. In stage 1 subjects were sent a questionnaire enquiring about respiratory symptoms and attacks of asthma in the last 12 months, current use of asthma medication and nasal allergies including hayfever. A random sample of subjects were selected to take part in stage 2 . Those who had already responded to stage 1 were invited to answer a more detailed administered questionnaire, and to take part in blood tests, skin tests, assessment of lung function by spirometry and airway challenge with methacholine. The questionnaire collected information on current smoking and smoking history.

\section{Methacholine challenge}

This is described in detail in the protocol [5]. Briefly, baseline forced expiratory volume in one second (FEV1) and forced vital capacity (FVC) were measured in all subjects who agreed. Subjects were advised to avoid smoking for $1 \mathrm{~h}$, using a $\beta_{2}$-agonist or anticholinergic inhaler for $4 \mathrm{~h}$ or oral medication $\left(\beta_{2}\right.$-agonist, theophylline or antimuscarinic) for $8 \mathrm{~h}$ before the test. When possible, subjects who reported a respiratory tract infection in the previous 3 weeks were rescheduled. 
Subjects were permitted nine attempts to provide at least two technically acceptable manoeuvres. All those whose FEV1 was at least $70 \%$ predicted [6] and $>1.5$ $\mathrm{L}$ were invited to undergo methacholine challenge unless they reported that they had heart disease, epilepsy, were pregnant or breastfeeding, or were taking a beta blocker.

Bronchial challenge commenced with inhalation of saline diluent, and the maximum post-diluent FEV1 recorded 2 min later was used as the control value. Those whose control FEV1 was $<90 \%$ of the baseline value were not challenged further. In all centres, methacholine was delivered using the Mefar dosimeter (Mefar, Bovezzo, Italy) set to deliver the aerosol over a period of $1 \mathrm{~s}$. Subjects were asked to expire to functional residual capacity, place their lips around the mouthpiece, inspire to total lung capacity, hold their breath for at least $3 \mathrm{~s}$ and then exhale. FEV1 was recorded $2 \mathrm{~min}$ later and in the absence of a $20 \%$ fall in FEV 1 from baseline the next dose was given. All solutions of methacholine were discarded and nebulizers refilled after 12 challenge tests.

Two methods of challenge were allowed by the protocol, each with a long and short schedule of doses (table 1 ). Method 1 started and terminated at a lower dose than Method 2. Those who denied respiratory symptoms suggestive of asthma received methacholine at quadrupling doses (short schedule) until a fall in FEV1 of $10 \%$ from the control value was recorded, after which doubling doses were used. All other subjects received doubling doses (long schedule). Two minutes after each inhalation subjects had up to five attempts to achieve two technically satisfactory FEV1 manoeuvres. The test was stopped if there was a greater than $20 \%$ fall in FEV1 from the control value, the maximum cumulative dose had been reached, the subject was not able to perform two technically satisfactory manoeuvres following any dose, or the subject did not wish to continue.

\section{Nebulizer weight calibration}

Weight output of each nebulizer was determined by filling the nebulizer with $3 \mathrm{~mL}$ of distilled water and weighing it. Ten inhalations were simulated by firing the dosimeter 10 times for $1 \mathrm{~s}$ duration and the nebuli-

Table 1. - The methacholine challenge doses for methods 1 and 2, long and short schedules, used in the European Community Respiratory Health Survey study

\begin{tabular}{|c|c|c|c|c|c|c|}
\hline \multirow[t]{3}{*}{$\begin{array}{l}\text { Dose } \\
\text { level }\end{array}$} & \multirow{3}{*}{$\begin{array}{l}\text { Concen- } \\
\text { tration } \\
\mathrm{mg} \cdot \mathrm{mL}^{-1}\end{array}$} & \multicolumn{4}{|c|}{$\begin{array}{l}\text { Number of } \\
\text { inhalations }\end{array}$} & \multirow{3}{*}{$\begin{array}{c}\text { Cumulative } \\
\text { dose mg } \\
\text { assuming } \\
0.01 \mathrm{~g} \\
\text { output }\end{array}$} \\
\hline & & \multicolumn{2}{|c|}{ Method 1} & \multicolumn{2}{|c|}{ Method 2} & \\
\hline & & Long & Short & Long & Short & \\
\hline 1 & 0.195 & 1 & - & - & - & 0.00195 \\
\hline 2 & 0.195 & 1 & 2 & - & - & 0.0039 \\
\hline 3 & 0.39 & 1 & - & 2 & - & 0.0078 \\
\hline 4 & 0.39 & 2 & 3 & 2 & 4 & 0.0156 \\
\hline 5 & 1.56 & 1 & - & 1 & - & 0.0312 \\
\hline 6 & 1.56 & 2 & 3 & 2 & 3 & 0.0625 \\
\hline 7 & 6.25 & 1 & - & 1 & - & 0.125 \\
\hline 8 & 6.25 & 2 & 3 & 2 & 3 & 0.25 \\
\hline 9 & 12.5 & 2 & - & 2 & - & 0.5 \\
\hline 10 & 12.5 & 4 & 6 & 4 & 6 & 1.0 \\
\hline 11 & 12.5 & - & - & 8 & 8 & 2.0 \\
\hline
\end{tabular}

zer reweighed. This was then repeated. The average output in gram per inhalation was then calculated.

\section{Statistical analysis}

Only the data from the doses common to the two methods, i.e. 0.0078-1 mg cumulative dose, were used (table 1 ). The provocative dose causing a $20 \%$ fall in FEV1 (PD20) was estimated by fitting an exponential curve to decline in maximum FEV1 with log dose [7]. An estimate greater than $5.1 \mu \mathrm{mol}(1 \mathrm{mg})$ was considered censored. A measure of slope was calculated by regressing percentage fall in FEV1 on $\log 10$ dose, referred to as log slope [8]. This measure was adopted in addition to PD20 to overcome a potential problem that might have resulted in percentage differences in the dose delivered in different centres [8]. Log slope and PD20 were estimated in two ways, first with the dose being calculated as if all nebulizers had constant and equal output of 0.01 g throughout the study (table 1), and second under the assumption that dose delivered by each nebulizer was directly related to the weight calibration for that nebulizer at the date subsequent to the test. To obtain the calibration-adjusted values the relevant individual nebulizer doses were increased by the percentage that the weight calibration exceeded $0.01 \mathrm{~g}$ and these were then added to give the cumulative dose. The weight calibration data were obtained from 28 of the 35 centres.

Log slope required transformation in order to satisfy the assumptions of standard statistical analysis, i.e. normality and homogeneity of variance; the transformation $100 /(\log$ slope +10$)$ was found to be appropriate [9]. The term "slope" is used for transformed log slope from now on.

In addition to adjustment for nebulizer weight calibration, the effect of nonresponse bias on the estimates was investigated; the same investigation was performed for total and specific immunoglobulin (Ig) E estimates [10]. Responders to stage 1 who did not respond to stage 2 were assumed to have the mean slope, or probability of PD20 $\leq 1 \mathrm{mg}$, as subjects of the same age group, sex and stage 1 symptoms. The nonresponse adjustment was applied to each estimate of slope and PD20, unadjusted and adjusted for nebulizer weight calibration. The effect of adjusting for baseline lung function was also investigated. The relation of slope to baseline FEV1 and FEV1 percentage predicted was estimated for men and women separately, allowing for centre differences, age group and smoking status, defined as current smoker, exsmoker or nonsmokers. Slope was adjusted using the regression coefficients to the gender-specific mean FEV1 and mean $\mathrm{FEV}_{1} \%$ pred.

Each measure of response was directly standardized to a population with uniform age and sex distribution, as used in summaries of symptom prevalence [11] and $\operatorname{IgE}$ data [10]. Slope adjusted for baseline lung function was also further standardized to $40 \%$ current smokers, $40 \%$ never smokers, and $20 \%$ exsmokers and unknown.

\section{Results}

Of the 48 centres which participated in stage 1 [11], five did not take part in stage 2. A further seven centres 


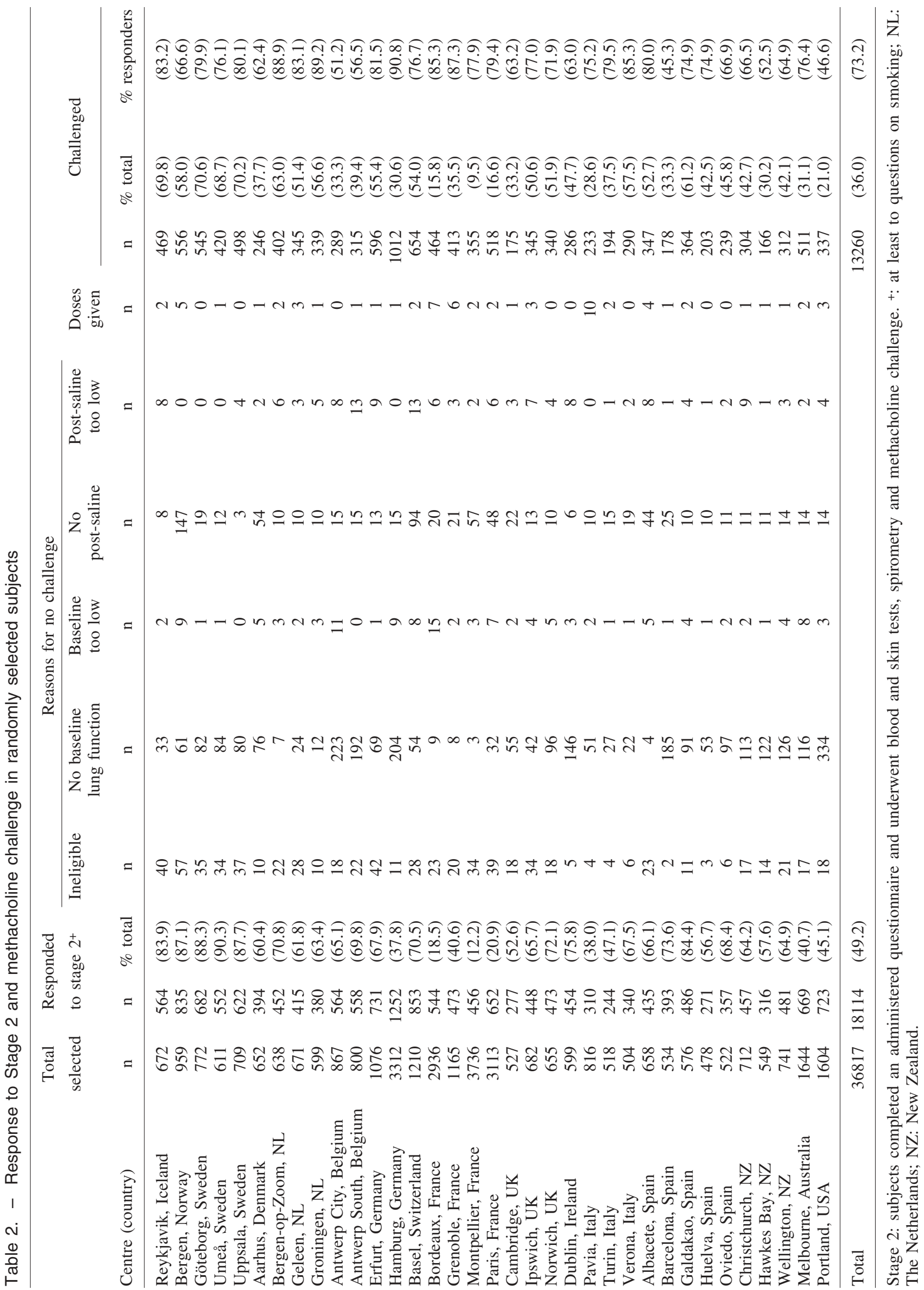


were excluded from this analysis, due to a different challenge protocol (one centre), challenge not performed (one centre), problems with Mefar dosimeter (one centre), data not fully checked and edited (three centres), insufficient response in one age group for age-sex standardization (one centre) or data not supplied in a usable form (one centre). Response to stage 2, defined as answering at least the main question on smoking, varied from $12.2 \%$ of those selected in Montpellier, to $90.3 \%$, in Umeå (table 2, second column). Of these, some were ineligible due to pregnancy or medication. The numbers who declined any participation in lung function testing are shown in the column headed "No baseline lung function" in table 2. Of those with baseline lung function, some had too low a value to proceed to challenge, and others declined challenge, either before or after the diluent inhalation. The percentage of those responding to stage 2 who were challenged varied from $45.3 \%$ in Barcelona, to $89.2 \%$ in Groningen;

Table 3. - Age-sex standardized bronchial responsiveness by centre, as measured by percentage of individuals with a provocative dose of methacholine causing a $20 \%$ fall in forced expiratory volume in one second $\left(F E V_{1}\right)$ of $\leq 1 \mathrm{mg}$, and by mean slope

\begin{tabular}{|c|c|c|c|c|}
\hline \multirow{2}{*}{$\begin{array}{l}\text { Centre } \\
\text { Reykjavik, Iceland }\end{array}$} & \multicolumn{2}{|c|}{$\mathrm{PD}_{20} \leq 1 \mathrm{mg}$} & \multicolumn{2}{|r|}{ Mean slope } \\
\hline & 7.2 & $(4.8-10.4)$ & $\mathrm{L}$ & $8.34(8.1$ \\
\hline Bergen, Norway & 8.0 & $(5.7-11.2)$ & $\mathrm{L}$ & $7.68(7.54-7.82)$ \\
\hline Göteborg, Sweden & 9.9 & $(7.3-13.2)$ & & $7.78(7.64-7.92) \mathrm{H}$ \\
\hline Umeå, Sweden & 11.8 & $(8.7-15.3)$ & & $7.65(7.46-7.84)$ \\
\hline Uppsala, Sweden & 7.7 & $(5.3-10.9)$ & $\mathrm{L}$ & $8.05(7.88-8.22) \mathrm{H}$ \\
\hline Aarhus, Denmark & 23.5 & $(17.1-28.7)$ & $\mathrm{H}$ & $7.28(7.02-7.55) \mathrm{L}$ \\
\hline Bergen-o-Z, NL & 10.8 & $(7.7-14.4)$ & & $7.75(7.56-7.94)$ \\
\hline Geleen, NL & 12.8 & (9.4-16.6) & & $7.40(7.20-7.60)$ \\
\hline Groningen, NL & 14.3 & $(10.6-18.1)$ & & $7.60(7.3$ \\
\hline Antwerp City, B & 14.4 & $(10.2$ & & $7.35(7$ \\
\hline Antwerp South, B & 13.0 & $(9.2-16.9)$ & & $7.63(7.38-7.88)$ \\
\hline Erfurt, Ger & 12.0 & $(9.4-15.3)$ & & $7.44(7.29-7.59) \mathrm{L}$ \\
\hline Hamburg, G & 17.5 & $(15.1$ & $\mathrm{H}$ & $7.21(7.0$ \\
\hline $\mathrm{Ba}$ & 9.8 & $.0)$ & $\mathrm{L}$ & $7.97(7.8$ \\
\hline Bordeaux, F & 23.2 & $(19.3$ & $\mathrm{H}$ & $6.77(6.5$ \\
\hline Grenoble, F & 16.3 & $(12.4-20.2)$ & $\mathrm{H}$ & $7.17(6.94-7.39) \mathrm{L}$ \\
\hline , F & 22.8 & $(17.9-27.3)$ & $\mathrm{H}$ & $6.93(6.67-7.18) \mathrm{L}$ \\
\hline & 12.0 & $(9.0-15.4)$ & & $7.85(7.6$ \\
\hline $\mathrm{C}$ & 27.6 & $(21$. & $\mathrm{H}$ & $6.66(6$. \\
\hline Ips & 16.6 & $(12.6-20.6)$ & & $7.18(6.9$ \\
\hline Norwich, UK & 15.5 & $(11.8-19.3)$ & & $7.69(7.46-7.92)$ \\
\hline Ireland & 16.6 & (12. & & $7.44(7.1$ \\
\hline & 9.3 & $(5.6-$ & & 8.17 \\
\hline & 11.6 & $6.0)$ & & 7.67 \\
\hline Verona, Italy & 10.3 & $(6.8-14.0)$ & & $7.88(7.67-8.09) \mathrm{H}$ \\
\hline Albecete, Spain & 21.3 & $(16.9-25.5)$ & $\mathrm{H}$ & $7.07(6.83-7.30) \mathrm{L}$ \\
\hline Barcelona, Spain & 11.6 & $(6.9-15.9)$ & & $7.87(7.56-8.18)$ \\
\hline $\mathrm{G}$ & 3.4 & $(1.6)$ & $\mathrm{L}$ & $8.44(8$ \\
\hline Hue & 7.7 & $(4.3-11.3)$ & $\mathrm{L}$ & $8.28(8.06-8.49) \mathrm{H}$ \\
\hline Oviedo, Spain & 8.5 & $(5.1-12.3)$ & $\mathrm{L}$ & $8.15(7.90-8.40) \mathrm{H}$ \\
\hline Christchurch, NZ & 27.6 & $(22.6-32.14)$ & $\mathrm{H}$ & $6.78(6.53-7.03) \mathrm{L}$ \\
\hline Hawkes-Bay, NZ & 27.8 & $(20.6-33.4)$ & $\mathrm{H}$ & $6.68(6.26-7.10) \mathrm{L}$ \\
\hline & 22.7 & (17.4-28.0) & $\mathrm{H}$ & $7.07(6.77-7.36) \mathrm{L}$ \\
\hline & 22.0 & $(18.3-25.9)$ & $\mathrm{H}$ & $6.97(6.79-7.15) \mathrm{L}$ \\
\hline Portland, USA & 18.3 & $(13.66-22.7)$ & $\mathrm{H}$ & $7.10(6.84-7.36) \mathrm{L}$ \\
\hline dian & & & & \\
\hline
\end{tabular}

Values in parentheses are $95 \%$ confidence intervals (95\% CI). L, H: 95\% CI excludes overall median, lower or higher respectively; Aust: Australia; B: Belgium; F: France; Ger: Germany; NL: The Netherlands; Bergen-o-Z: Bergen-op-Zoom; NZ: New Zealand. See text for definition of mean slope. the total number challenged was 13,260. A few further subjects were excluded, due to a nebulizer calibration in one centre, only a single dose of methacholine being given, or data found to be in error. There were 13,161 subjects with usable data.

Age-sex standardized bronchial responsiveness is shown by centre in table 3, without adjustment for nebulizer weight output or nonresponse. Each centre is classified on each measure according to whether the $95 \%$ confidence interval $(95 \% \mathrm{CI})$ excluded the median for the 35 centres. A "high" value for prevalence of PD20 $\leq 1 \mathrm{mg}$ corresponds to a "low" mean slope, and in general centres classified as low or high on PD20 are classified as high or low respectively on mean slope. However, as slope is a continuous measure the $95 \%$ CI for the means are relatively narrower than those for prevalences, so some centres are classified as high or low mean slope while the $95 \%$ CI for percentage prevalence PD20 includes the median of $13 \%$.

Centres which had an unequivocally high level of bronchial responsiveness were: Hamburg, Germany; Aarhus, Denmark; Bordeaux, Grenoble and Montpellier, France; Cambridge, UK; Albacete, Spain; and all five non-European centres, the three in New Zealand, one in Australia and one in the USA. Centres with an unequivocally low level were: Reykjavik, Iceland; Basel, Switzerland; Uppsala, Sweden; and three Spanish centres, Galdakao, Oviedo and Huelva. The centre that was an exception to the overall agreement between the two measures was Bergen, Norway, which was classified as low by PD20 and average by mean slope. The correlation of the two unadjusted measures across the centres was -0.94 .

Age-sex adjusted mean slope for each centre is plotted in figure 1 by country, with countries with a low level of bronchial responsiveness, equivalent to a high mean slope, to the left on the abscissa. Iceland, Switzerland, Sweden, Spain and Italy had low levels of responsiveness. Albacete was an outlier in the Spanish results. Germany, Denmark, France, Britain, the USA,


Fig. 1. - Mean slope for each centre by country. $\circ$ : centre with $95 \%$ confidence interval $(95 \% \mathrm{CI})$ for the mean above and excluding the study median (low responsiveness); $\oplus: 95 \% \mathrm{CI}$ for the mean including the study median; and $\bullet: 95 \%$ CI below and excluding the study median (high responsiveness). 
Table 4. - Change in percentage prevalence PD20 and mean slope due to adjustments for nonresponse and nebulizer weight calibrations

\begin{tabular}{lcccc}
\hline & \multicolumn{4}{c}{ Difference from unadjusted value } \\
\cline { 3 - 5 } & $\mathrm{n}$ & Mean & SD & SEM \\
\hline PD20 & & & & \\
Adjusted for: & & & & \\
$\quad$ Nonresponse & 35 & $-0.48^{*}$ & 1.17 & 0.20 \\
$\quad$ Weight calibration & 28 & $-1.80^{* * *}$ & 1.57 & 0.30 \\
$\quad$ Both & 28 & $-2.14^{* * *}$ & 1.94 & 0.37 \\
Mean slope & & & & \\
Adjusted for: & & & & \\
$\quad$ Nonresponse & 35 & $0.04 * * *$ & 0.07 & 0.01 \\
$\quad$ Weight calibration & 28 & 0.00 & 0.10 & 0.02 \\
$\quad$ Both & 28 & 0.02 & 0.09 & 0.02 \\
Baseline FEV1 & 35 & -0.03 & 0.13 & 0.02 \\
Baseline FEV1 and & & & & \\
smoking prevalence & 35 & -0.04 & 0.14 & 0.02 \\
\hline
\end{tabular}

$*, * * *: \mathrm{p}<0.05, \mathrm{p}<0.001$, mean change significantly different from zero. FEV1: forced expiratory volume in one second; PD20: provocative dose of methacholine causing a $20 \%$ fall in FEV1.

Australia and New Zealand have high levels of responsiveness.

The effect of adjusting for nonresponse and nebulizer weight output is shown in table 4. Adjustment for nonresponse in centres with a low response rate decreased the prevalence of PD20 $\leq 1 \mathrm{mg}$, and increased mean slope, as people with symptoms were more likely to take part in stage 2 and to be reactive. Figure 2 shows the effect on mean slope. The biggest adjustments were for Montpellier, Bordeaux and Hamburg, which had low response rates to stage 2 (table 2), especially the French centres. However, across the centres the correlation between the unadjusted and nonresponse adjusted measures was 0.98 for slope and 0.99 for PD20, so there was little effect of nonresponse on the ranking of the centres. Adjustment for nebulizer weight calibration, for the 28 centres that supplied the data, significantly decreased the PD20 prevalence (table 4), but mean slope did not increase significantly, either for the weight calibration adjustment alone or the combination with nonresponse adjustment. The correlation between the nonresponse adjusted measures of slope and PD20

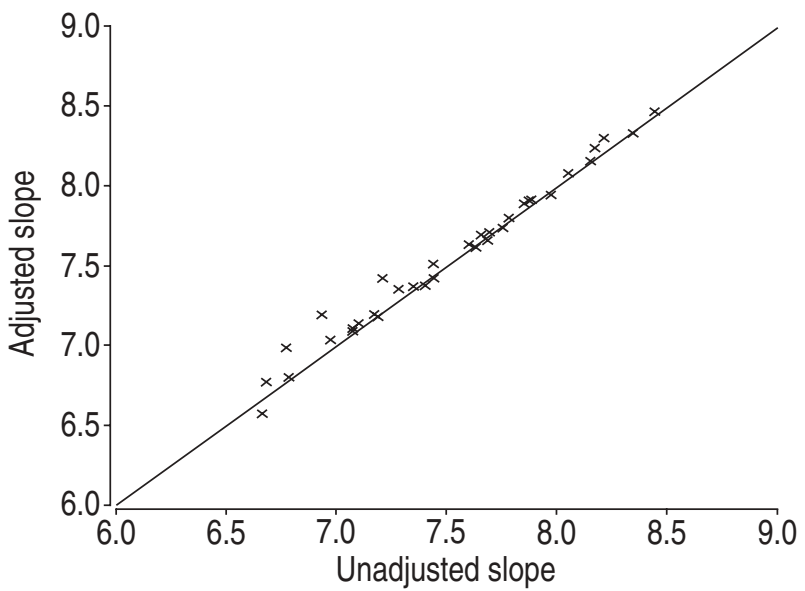

Fig. 2. - The relationship of mean slope adjusted for nonresponse to unadjusted mean slope for 35 centres. - : line of identity. was -0.94 , and fell to -0.83 for the nonresponse and weight calibration adjusted values.

Adjustment of slopes for baseline lung function, or with standardization for smoking prevalence in addition, resulted in changes to centre means with a standard deviation comparable to the weight calibration adjustment (table 4). The correlations with unadjusted mean slope were 0.97 and 0.96 respectively. As slope was shown to be the more sensitive measure for centre comparison, and has other advantages, the corresponding analysis for PD20 was not carried out.

\section{Discussion}

This is the first report of truly comparative data on bronchial responsiveness in adults from different countries. It documents high levels of responsiveness in centres in New Zealand, Australia, the United States and Britain, which parallel high prevalence of respiratory symptoms in these centres [11], but also in France and Germany. Low levels of responsiveness were found in Iceland and Switzerland, and in most centres in Sweden, Italy and Spain. The Icelandic centre and Pavia and Verona in Italy also had low symptom prevalence [11].

These findings are largely independent of whether PD20 or slope is used as a summary statistic. Each has its merits and weaknesses. PD20 is used extensively, and is easy to comprehend. However, either information is lost in analysis by defining each subject as responsive or not, or methods for censored data must be used, either as described by CHINN et al. [12] or the "survival" method of SUNYER et al. [13].

Many factors influence the actual dose of methacholine inhaled during bronchial challenge testing. In multicentre studies, systematic differences between centres in the dose delivered may result in spuriously large variations in bronchial responsiveness. Log dose is not influenced by a problem that results in a constant overor underestimation of the aerosol output of the nebulizer [8]. As far as possible, other factors (inhalation time, breath-hold time and time between doses) were standardized. In addition, because nebulization with jet nebulizers results in evaporation and concentration of solutions, all nebulizers were emptied and refilled after 12 tests. As part of the quality control programme, centres were visited by personnel from another centre or the co-ordinating team to ensure that the protocol was followed.

In contrast to the dose-response slope defined elsewhere $[12,14,15]$, which like PD20 is also affected by nebulizer batch variation [8], log slope can be transformed to a reasonably normal distribution [9], and it is this transformed slope that is termed "slope" here. Its great advantage is that it is relatively unaffected by the use of different batches of nebulizers in different centres, provided the same batch was in use at any one time. Although a post-study calibration of nebulizers found less variation [8] than had been previously suggested [16], the five nebulizers used in Bergen, Norway, were detected as outliers in that analysis [8]. This may explain why Bergen is the one centre for which percentage prevalence PD20 and mean slope appear to conflict, and suggests that slope should be used for 
comparisons. The result for Albacete was an outlier in Spain, in terms of slope and PD20, and no explanation has so far been found. Slope is easy to analyse, and mean slope in this study was found to have narrower confidence intervals than percentage prevalence PD20 relative to the between-centre variation. Its drawbacks are its dependence on the dose schedule, as the relationship between percentage fall and log dose is not strictly linear, and its unfamiliarity. However, any comparative study should use a common protocol, the previous prevalence studies being difficult to compare even between those reporting PD20 for methacholine [1].

Both PD20 and mean slope were affected by nonresponse bias in the few centres with very low response rates. However, even in these centres the effect was small compared to the overall between-centre variation (fig. 2). The adjustments for nonresponse took into account variation in the percentage of subjects excluded on protocol criteria as well as nonresponse to stage 2 . We have reported the unadjusted results in detail (table 3 ), as the effect was small, and this is in line with our other results from the study $[10,11]$. None of the measures should be considered absolute. It is the relative results for the centres that are of interest, and so the correlation between the measures is of more interest than any shift produced by adjustment for nonresponse or other standardization.

Adjustment for weight calibration affected PD20, but not slope, as expected from detailed study of the British data [8]. This is another advantage of slope, and further reason for the presentation of slope as weight calibration data were not supplied by all centres.

The maximum dose of methacholine common to all the protocols was $1 \mathrm{mg}(5.1 \mu \mathrm{mol})$, which is lower than that used elsewhere [1]. Although the majority of centres continued to $2 \mathrm{mg}$, or $4 \mathrm{mg}$ in a few centres, estimation of PD20 was restricted to the common doses to ensure comparability, and because VerLato et al. [17] concluded that extrapolation should not be used.

The sensitivity of mean slope to variation in baseline lung function and smoking between centres was investigated, as several authors have found that PD20 is dependent on baseline lung function [17-21] and related to smoking [21-25]. The average within-centre relationship of slope to baseline FEV1 and FEV1\% pred was used, and resulted in little change to the conclusions. These relationships differed between centres, and they will be the subject of further extensive analyses of risk factors for bronchial responsiveness, so the results presented here are unadjusted for baseline lung function. The effect of variation in smoking prevalence was also minimal. Direct age-sex standardization was used, to preclude effects of age and sex, although not all the studies cited found a relationship for bronchial responsiveness to age and sex.

There can be no absolute definition of who is "responsive" and who is not. The problem of defining the dose of methacholine administered goes beyond calibration of nebulizers in output by weight and aerosol output, as this does not lead to a measure of the concentration in the airways. Any definition of responsiveness is, therefore, somewhat arbitrary. PD20 can be used in comparative studies provided a common protocol and standardized equipment are used, but it encourages the idea of two separate populations and relatively small departures from standardized equipment or procedures may make the comparisons invalid. CоскCROFT et al. [26] described bronchial responsiveness as a continuum in 1983, which was further endorsed by RIJCKEN et al. [27]. This may have stimulated the search for a continuous summary measure. Dose-response slope as proposed by O'CONNOR et al. [15] or ABRAMSOn et al. [14] may not add to the information provided by PD20 [12], and does not overcome the potential nebulizer batch variation problem identified by DeNNIS et al. [16]. Slope as defined here, the regression coefficient of percentage decline in FEV1 on log dose, transformed using a reciprocal transformation, provides a continuous measure that is robust to nebulizer batch variation between centres. Slope and PD20 are complementary measures, but show good agreement in identifying centres and countries with high and low levels of responsiveness.

BURR et al. [2] compared exercise challenge in 1112 yr old children in Sweden, Wales, South Africa and New Zealand, finding the greatest fall in peak expiratory flow rate in New Zealand and least in Sweden. Our results not only extend this finding on bronchial responsiveness to adults but provide a comparison between 16 countries. While broadly in agreement with symptom variation [11], the complex relationship between bronchial responsiveness, symptoms and risk factors will be the subject of further detailed analysis.

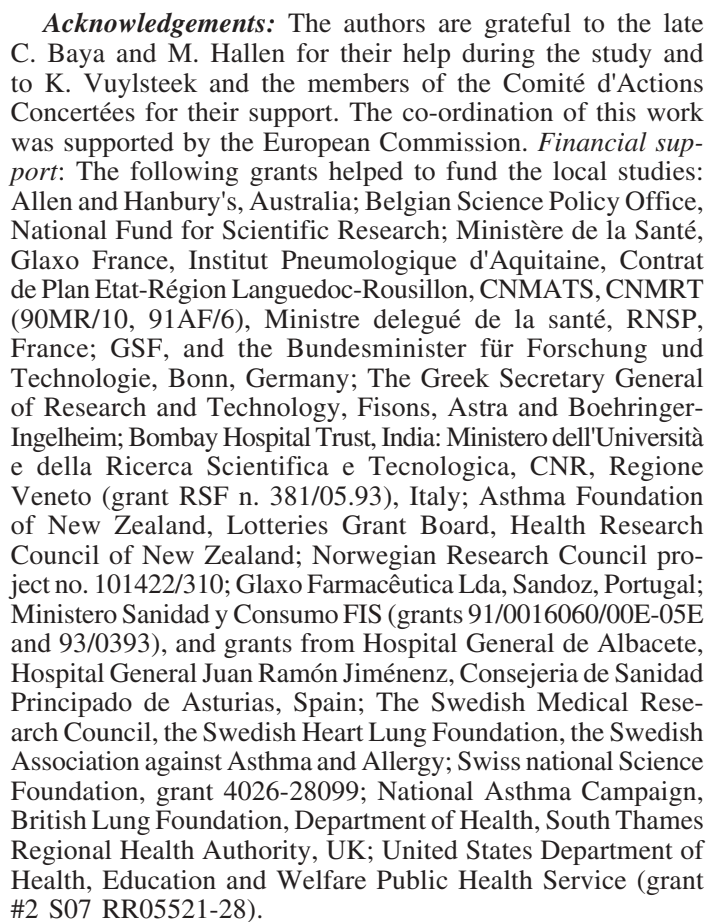

List of principal participants:

Co-ordinating Centre (London): P. Burney, S. Chinn, C. Luczynska, D. Jarvis, E. Lai.

Project Management Group: P. Burney (Project leader); S. Chinn, C. Luczynska, D. Jarvis, P. Vermeire (Antwerp); H. Kesteloot (Leuven); J. Bousquet (Montpellier); D. Nowak (Hamburg); the late J. Prichard (Dublin); R. de Marco (Verona); B. Rijcken (Groningen); J.M. Anto (Barcelona); J. Alves (Oporto); G. Boman (Uppsala); N. Nielsen (Copenhagen); P. Paoletti (Pisa). 
Participating centres: W. Popp (Vienna, Austria); M. Abramson, J. Kutin (Melbourne, Australia); P. Vermeire, F. van Bastelaer (Antwerp South, Antwerp Central, Belgium); J. Bousquet, J. Knani (Montpellier), F. Neukirch, R. Liard (Paris), I. Pin, C. Pison (Grenoble), A. Taytard (Bordeaux, France); H. Magnussen, D. Nowak (Hamburg), H.E. Wichmann, J. Heinrich (Erfurt, Germany); N. Papageorgiou, P. Avarlis, M. Gaga, C. Marossis (Athens, Greece); T. Gislason D. Gislason (Reykjavik, Iceland); J. Prichard, S. Allwright, D. MacLeod (Dublin, Ireland); M. Bugiani, C. Bucca, C. Romano (Turin), R. de Marco Lo Cascio, C. Campello (Verona), A. Marinoni, T. Cerveri, L. Casali (Pavia, Italy); B. Rijcken, A. Kremer (Groningen, Bergen-op-Zoom, Geleen, The Netherlands); J. Crane, S. Lewis (Wellington, Christchurch, Hawkes Bay, New Zealand); A. Gulsvik, E. Omenaas (Bergen, Norway); J.A. Marques, J. Alves (Oporto, Portugal); J.M. Antó, J. Sunyer, F. Burgos, J. Castellsagué, J. Roca, J.B. Soriano, A. Tobías (Barcelona), N. Muniozguren, J. Ramos González, A. Capelastegui (Galdakao), J. Castillo, J. Rodriguez Portal (Seville), J. Martinez-Moratalla, E. Almar (Albacete), J. Maldonado Pérez, A. Pereira, J. Sánchez (Huelva), J. Quiros, I. Huerta, F. Pavo (Oviedo, Spain); G. Boman, C. Janson, E. Björnsson (Uppsala), L. Rosenhall, E. Norrman B. Lundbäck (Umeå), N. Lindholm, P. Plaschke (Göteborg, Sweden); U. Ackermann-Liebrich, N. Künzli, A. Perruchoud (Basel, Switzerland); M. Burr, J. Layzell (Caerphilly), R. Hall (Ipswich), B. Harrison (Norwich), J. Stark (Cambridge, UK); S. Buist, W. Vollmer, M. Osborne (Portland, USA).

\section{References}

1. Neukirch F, Cartier A. Mesure de l'hyperreactivite bronchique en epidemiologic. Rev Mal Resp 1994; 11: 101-109.

2. Burr ML, Limb ES, Andrae S, Barry DM, Nagal F. Childhood asthma in four countries: a comparative study. Int J Epidemiol 1994; 23: 341-347.

3. Asher MI, Pattemore PK, Harrison AC, et al. International comparison of the prevalence of asthma symptoms and bronchial hyperresponsiveness. Am Rev Respir Dis 1988; 138: 524-529.

4. Burney PGJ, Luczynska C, Chinn S, Jarvis D. The European Community Respiratory Health Survey. Eur Respir J 1994; 7: 954-960.

5. United Medical and Dental Schools of Guy's and St. Thomas's Hospitals, Department of Public Health Medicine. Protocol for The European Community Respiratory Health Survey. ISBN 1869942019 London 1993.

6. Quanjer PhH, Tammeling GJ, Cotes JE, Pedersen OF, Peslin R, Yernault J-C. Lung volumes and forced ventilatory flows. Eur Respir J 1993; 6 (Suppl. 16): 5-40.

7. Chinn S, Britton JR, Burney PGJ, Tattersfield AK, Papacosta AO. Estimation and repeatability of the response to inhaled histamine in a community survey. Thorax 1987; 42: 45-52.

8. Chinn S, Arossa WA, Jarvis DL, Luczynska CM, Burney PGJ. Variation in nebuliser aerosul output and weight output from the Mefar dosimeter: implications for multicentre studies. Eur Respir J 1997; 10: 452-456.

9. Chinn S. Choosing a transformation. J Appl Stat 1996; 23: 395-404.

10. European Community Respiratory Health Survey. The distribution of total and specific serum IgE in the European Community Respiratory Health Survey. J Allergy Clin Immunol 1997; 99: 314-322.

11. European Community Respiratory Health Survey. Variations in the prevalence of respiratory symptoms, self-reported asthma attacks and use of asthma medication in the European Community Respiratory Health Survey (ECRHS). Eur Respir J 1996; 9: 687-695.
12. Chinn S, Burney PGJ, Britton JR, Tattersfield AK, Higgins BG. Comparison of PD20 with two alternative measures of response to histamine challenge in epidemiological studies. Eur Respir J 1993; 6: 670-679.

13. Sunyer J, Munoz A, and the Spanish Group of the European Asthma Study. Concentrations of methacholine for bronchial responsiveness according to symptoms, smoking and immunoglobulin $\mathrm{E}$ in a population-based study in Spain. Am J Respir Crit Care Med 1996; 153 : 1273-1279.

14. Abramson MJ, Saunders NA, Hensley MJ. Analysis of bronchial reactivity in epidemiological studies. Thorax 1990; 45: 924-929.

15. O'Connor G, Sparrow D, Taylor D, Segal M, Weiss S. Analysis of dose-response curves to methacholine. Am Rev Respir Dis 1987; 136: 1412-1417.

16. Dennis JH, Avery AJ, Walters EH, Hendrick DJ. Calibration of aerosol output from the Mefar dosimeter: implications for epidemiological studies. Eur Respir J 1992; 5: 1279-1282.

17. Verlato G, Cerveri I, Villani A, et al. Evaluation of methacholine dose-response curves by linear and exponential mathematical models: goodness-of-fit and validity of extrapolation. Eur Respir J 1996; 9: 506-511.

18. Malo J-L, Pineau L, Cartier A, Martin RR. Reference values of the provocative concentrations that cause $6 \%$ and $20 \%$ changes in forced expiratory volume in one second in a normal population. Am Rev Respir Dis 1983; 126: 8-11.

19. Rijcken B, Schouten JP, Weiss ST, Speizer FE, van der Lende $\mathrm{R}$. The relationship between airway responsiveness to histamine and pulmonary function level in a random population sample. Am Rev Respir Dis 1988; 137: 826-832.

20. Trigg CJ, Bennett JB, Tooley M, Sibbald B, D'Souza MFD, Davies RJ. A general practice based survey of bronchial hyperresponsiveness and its relation to symptoms, sex, age, and smoking. Thorax 1990; 45: 866-872.

21. Bakke PS, Baste V, Gulsvik A. Bronchial responsiveness in a Norwegian community. Am Rev Respir Dis 1991; 143: 317-322.

22. Paoletti P, Carrozzi L, Viegi G, et al. Distribution of bronchial responsiveness in a general population: effect of sex, age, smoking, and level of pulmonary function. Am J Respir Crit Care Med 1995; 151: 1770-1777.

23. Burney PGJ, Britton JR, Chinn S, et al. Descriptive epidemiology of bronchial reactivity in an adult population: results from a community study. Thorax 1987; 42: 38-44.

24. Cerveri I, Bruschi C, Zoia MC, et al. Smoking habit and bronchial reactivity in normal subjects. Am Rev Respir Dis 1989; 140: 191-196.

25. Peat JK, Salome CM, Woolcock AJ. Factors associated with bronchial hyperresponsiveness in Australian adults and children. Eur Respir J 1992; 5: 921-929.

26. Cockcroft DW, Bersheid BA, Murdock KY. Unimodal distribution of bronchial responsiveness to inhaled histamine in a random human population. Chest 1983; 83: 751-754.

27. Rijcken B, Schouten JP, Weiss ST, Neinesz AF, de Vries K, van der Lende R. The distribution of bronchial responsiveness to histamine in symptomatic and asymptomatic subjects. Am Rev Respir Dis 1989; 140: 615-623. 